\title{
The development of a classification system for maternity models of care
}

\author{
Natasha Donnolley, BSc(HIM), CHIM', \\ Kerryn Butler-Henderson, $B S C(H I M), G C T T, M P H, P h D, C H I M, C H I A, F A C H I^{2}$, \\ Michael Chapman, MBBS, MD, FRCOG, FRANZCOG, CREI', \\ Elizabeth Sullivan, MD, MBBS, MPH, MMed(Sexual Health), FAFPHM ${ }^{1,3}$
}

\begin{abstract}
Background: A lack of standard terminology or means to identify and define models of maternity care in Australia has prevented accurate evaluations of outcomes for mothers and babies in different models of maternity care. Objective: As part of the Commonwealth-funded National Maternity Data Development Project, a classification system was developed utilising a data set specification that defines characteristics of models of maternity care. Method: The Maternity Care Classification System or MaCCS was developed using a participatory action research design that built upon the published and grey literature. Results: The study identified the characteristics that differentiate models of care and classifies models into eleven different Major Model Categories. Conclusion: The MaCCS will enable individual health services, local health districts (networks), jurisdictional and national health authorities to make better informed decisions for planning, policy development and delivery of maternity services in Australia.
\end{abstract}

\section{Keywords (MeSH)}

classification; data collection; health information systems; health care evaluation mechanisms; perinatal care; patient care bundles

\section{Introduction}

In 2012 over 307,000 mothers gave birth to more than 312,000 babies in Australia (Hilder et al. 2014). Childbirth and obstetric procedures represent almost $6 \%$ of separations in Australian hospitals and are responsible for the two most common principal diagnoses for overnight acute separations (Australian Institute of Health and Welfare 2015). This is a significant cost to the health system, particularly in terms of patient days: $1,014,607$ in 2013-14 (Australian Institute of Health and Welfare 2015). Differences in length of stay are observed between states and territories, and between the public and private health sectors, and this could in part be attributed to different models of care. Economic analyses undertaken in a number of different studies comparing midwifery-led models of care to other models of maternity care have shown reduced costs associated with the former (Sandall et al. 2013).

In 2008, the Commonwealth Department of Health and Ageing undertook a review of maternity services in Australia. Despite having maternal and perinatal mortality rates that compared with the lowest in the world (World Health Organization 2011), it was recognised that there were improvements to be made to meet the needs of Australian birthing women (Commonwealth of Australia 2009). The review consulted widely with a range of stakeholders to identify key gaps in service provision, what changes were needed and what resources were required for that change to occur. The information collected from the review was used to inform the priorities for a national action plan.

One of the findings of the national Maternity Services Review was that a majority of women received their maternity care in one of four broad models: private maternity care, combined maternity care, public hospital care and shared maternity care (Commonwealth of Australia 2009). The report also acknowledged that although there were a range of different models of care around the country, there was a lack of clear definitions or terminology to identify what those models were and that consumers were

\footnotetext{
' School of Women's and Children's Health, University of New South Wales, Sydney, Australia

${ }^{2}$ Australian Institute of Health Service Management, University of Tasmania, Launceston, Australia

${ }^{3}$ Faculty of Health, University of Technology Sydney, Sydney, Australia
}

Accepted for publication September 26, 2015.

Corresponding author:

Natasha Donnolley, National Perinatal Epidemiology and Statistics Unit, School of Women's and Children's Health, UNSW Medicine, University of New South Wales, Sydney NSW, Australia.

Email: n.donnolley@unsw.edu.au 
dissatisfied about their level of access to different models. The lack of standard terminology makes it difficult for consumers to make clear informed choices, for health service providers to provide a range of models and for an accurate evaluation or comparison of different models of maternity care. This inability to define models of care was also identified during a review of existing Australian maternity data collections by the National Perinatal Epidemiology and Statistics Unit (NPESU) in 2009. The NPESU review identified key data gaps, including the lack of nationally agreed definitions for models of maternity care that take into account variations in service delivery between institutions and jurisdictions (Walker 2011).

In response to the Maternity Services Review, the former Commonwealth Department of Health and Ageing developed and launched the five-year National Maternity Services Plan (The Plan) in 2010 (Australian Health Ministers' Conference 2011). The Plan provided a strategic framework for the jurisdictional and federal governments to guide a coordinated approach to the development of improved policy and services for maternity care in Australia. The actions contained in The Plan were far-reaching and aimed to address the disparity in availability of different services around the country and for different groups of women. Many of the actions contained in The Plan relied on the availability of consistent information on maternal and perinatal outcomes (including morbidity and mortality data) and models of maternity care.

One of the programs initiated to support The Plan was the National Maternity Data Development Project (NMDDP) (Australian Institute of Health and Welfare 2014a). The NMDDP was a collaborative project conducted by the Australian Institute of Health and Welfare and NPESU between 2011 and 2015 to develop a nationally consistent and expanded maternal and perinatal morbidity and mortality data collection in Australia. One component of this was to develop a standardised nomenclature and definitions for models of maternity care. An initial investigation by the NPESU determined that no such system was in place anywhere in the world and would need to be developed (Australian Institute of Health and Welfare 2014b).

A 'model of care' is a term that is thought to have its origins in the nursing profession (Homer, Brodie \& Leap 2008) and while it is a term often used in healthcare it is not easy to define. One of the clearest published definitions is that a model of care is 'a multifaceted concept, which broadly defines the way health services are delivered' (Queensland Health 2000: 4). Providing care in 'models' allows for a standardised approach to healthcare so that staff understand a consistent method to providing the care using a similar framework and standards, and consumers have a better understanding what their 'package' of care provides. It is a way of standardising care in a systematic way and encompasses both tangible concepts such as roles, methods, location and structure of care, and less tangible or measurable concepts such as philosophy, culture and values (Davidson et al. 2006). Models of care may also be referred to as 'care bundles'.

\section{Aim}

The aim of this project was to develop a systematic nomenclature that would encompass the range of models of maternity care available now and in the future throughout Australia. This system would enable evaluation and analysis of the outcomes for women and babies under different models of care. This would contribute directly to a number of actions in The Plan including: reporting of Action 1.1.3National Core Maternity Indicators (Indicator 20); Action 4.2.4 - the development of 'consistent descriptors and definitions for the range of models of maternity care available' (Australian Health Ministers' Conference 2011: 53); and Action 4.1.5 - the development of standardised nationally consistent maternal and perinatal data collections. Without standardised collection and reporting of data on models of care there is no way to effectively manage, monitor or change practices or accurately measure outcomes for women and babies in different models of care.

\section{Method}

The project commenced in July 2011 and was conducted over two stages (see Figure 1). Stage 1 (2011-2013) constituted concept development; identifying the characteristics of models of maternity care, reviewing the literature, development of a data framework and consulting with stakeholders. Stage 2 (2011-2015) involved further consultation, technical data development of a data set specification and validation of the content and metadata through a national pilot program.

\section{Stage 1}

The concept of defining models of maternity care through a simple naming system originated following the national Maternity Services Review (Commonwealth of Australia 2009). However, after commencing the literature review, (including jurisdictional and national health policy documents, published research and grey literature) it was soon apparent to the project team that models of care were a far too complex construct to be indentifiable by name only. Variations within model categories meant even the development of definitions would not be sufficient to differentiate adequately between them to a level of granularity that would allow meaningful analysis of outcomes under different models of care.

According to Amatayakul (2009), a 'nomenclature' can be as simple as a body of terms and their definitions. In this context, the literature review identified a set of different categories or types of broad models of maternity care along with some general definitions. These were named the 'Major Model Categories' (MMC) and are useful for standardising the terminology and names of different models of care around Australia. The literature review and the consultations undertaken in each of the states and territories identified that the terminology in place at the time had different meanings in different places and there was no common understanding of what different models of care 


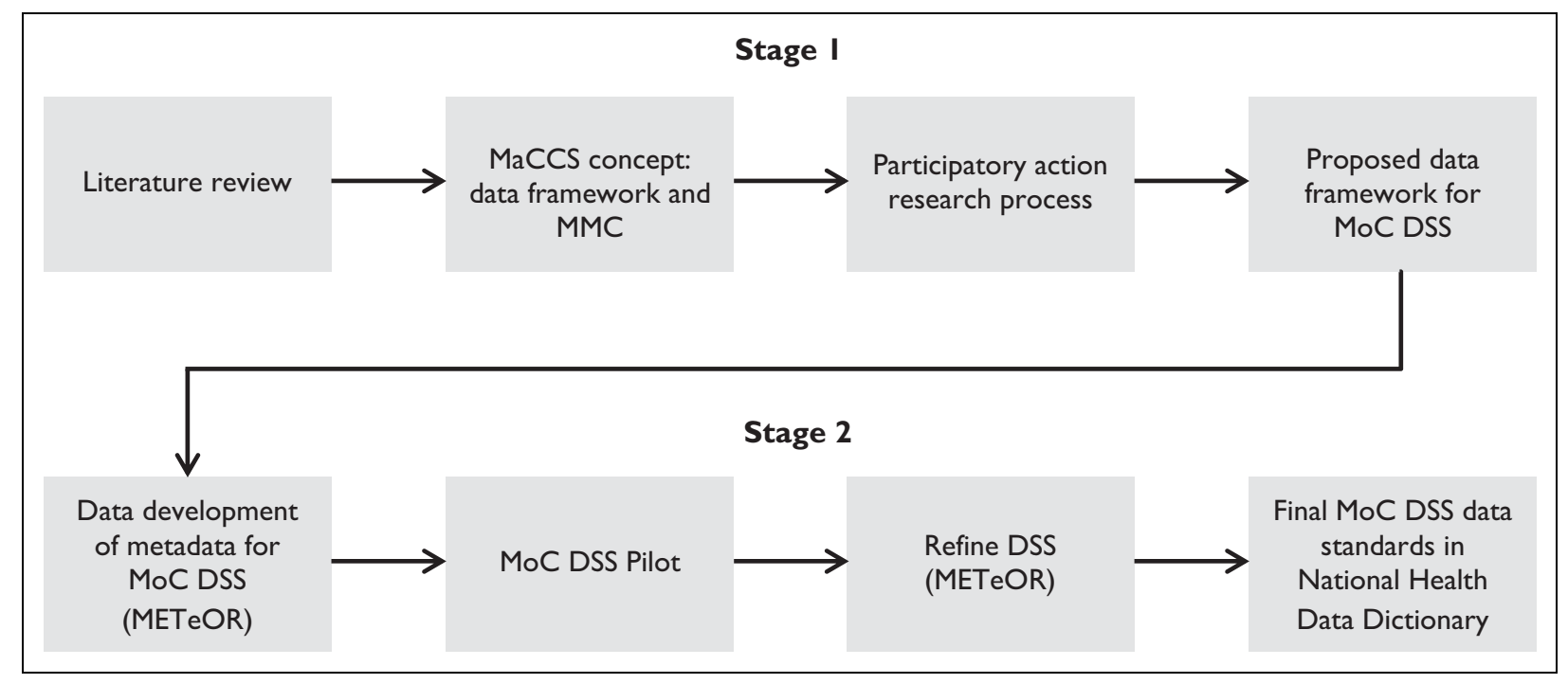

Figure I. Stage I and 2 MaCCS development process.

included around the country. The MMC provide a common understanding of the broad 'ingredients' for different models of care and are a major step forward in addressing the inconsistencies around Australia in the definitions of different model categories.

As stated, although a simple nomenclature was identified through the literature review and the stakeholder consultations, it lacked sufficient granularity to be used for comparing women in 'like' models of care due to the significant heterogeneity of models within the same MMC. This variation in models of the same type was highlighted in the Cochrane systematic review of midwifery-led versus other models of care (Sandall et al. 2013). Large variation between models of the same type can result in incorrect comparisons being made if there are differences in the model characteristics that might impact on women's care and outcomes. For example, one 'Midwifery Group Practice Caseload' model could provide care just for 'low risk' women and another 'Midwifery Group Practice Caseload' model could provide care for women of all obstetric risk. Comparing the women in these two models would not be valid as their outcomes are likely to be different due to their differing risk status. Similarly, two 'Team Midwifery' models may have different numbers of midwives providing the care; one could have three midwives, the other 20 midwives. This difference between two models of the same type has the potential to impact on the continuity of care provided to women, and subsequently the women's experiences and perinatal outcomes (Australian Institute of Health and Welfare 2014b). In both of these examples, incorrect conclusions could be made if an analysis of the outcomes was based purely on the model category as the comparison is not grouping 'like with like'.

Recognising that a simple 'nomenclature' was insufficient to meet the aims of the project, the concept of a data framework based on the different characteristics of models of care was developed. The data framework was based around three dimensions: the women the model was targeted at; the professionals working in the model; and aspects of the care provided by the model. The literature review was then expanded to identify the characteristics that differentiated between models of care, regardless of their name or MMC.

The MMC were then combined with the draft framework of data items based on the characteristics of models of care to form the concept of a classification system. This became known as the Maternity Care Classification System (MaCCS). The benefits of 'classification' are that objects can be grouped based on logical similarities (the data framework) for the purposes of communication using standard terminology in addition to statistical analysis (Jutel 2011).

Using a participatory action research design (Baum et al. 2006) the proposed data framework and the MaCCS were presented to stakeholders in each jurisdiction (state or territory responsible for the provision of healthcare), including health department policy staff, midwives, obstetricians, administrators, maternity academics and consumers. The aim of the consultation forums was to engage with potential users and content experts to discuss, review and modify the data elements so that they were relevant and acceptable to all contexts and jurisdictions. Differences in service delivery and terminology between the jurisdictions meant that additional values were added and definitions altered to meet the different requirements and some data elements were removed or replaced by new ones. The benefit of participatory action research is that the participants become the researchers and contribute to the design and output of the project, resulting in more relevant and accurate data items being developed.

Following the cycle of face-to-face consultation forums the resulting data framework and MaCCS concept were then distributed for comment nationally via an electronic survey. This was conducted using SurveyMonkey ${ }^{\circledR}$ through a range of national organisations and distribution networks to ensure the widest possible reach. Feedback from the survey was then incorporated into the final round of consultations and amendments to the proposed data items. 


\section{Stage 2}

To ensure that data collected through the MaCCS were comparable regardless of the collection point or method, the final version of the data framework underwent formal data development. This involved the development of a set of data standards for each of the proposed data items (informed by the process undertaken in Stage 1) which together form a data set specification (DSS). This was undertaken using the Australian Institute of Health and Welfare Metadata Online Repository (METeOR) to develop the metadata that form each of the data items. Metadata is 'data about data' and includes specifications for defining how the data should be collected; the format (numerical, string etc.), the definition, scope and permissible values for each of the data elements. METeOR is both an application to develop as well as a repository to store metadata for future use and conforms to ISO/IEC 11179 (2003) standards (Australian Institute of Health and Welfare 2007). Developing data standards for the MaCCS data framework resulted in data elements that can be used individually or as part of the full DSS and that data collected using the standards are consistent, comparable and meaningful.

Although the contents of the MaCCS data framework underwent considerable consultation in Stage 1, the data standards in METeOR include further instructions about usage, permissible values and conditional statements that then required further feedback from potential users. To ensure that the data standards were complete and inclusive of all potential values and that the definitions and guide for use information were comprehensive, the draft Maternity Model of Care DSS (MoC DSS) was then evaluated through a national pilot program. Using maternity services nominated by each jurisdiction's health department, the MoC DSS was piloted in 47 sites across Australia using an electronic survey tool (SurveyMonkey ${ }^{\circledR}$ ). Maternity Unit Managers (or equivalent) were invited to participate in the pilot and to classify each of the models of maternity care they offered at their service using the questionnaire. Participants were asked to provide feedback on each of the data elements, including whether there were difficulties answering the questions, whether additional values were required or whether there were any comments to improve the data standards.

An analysis of the pilot data was then undertaken to identify whether any of the metadata needed updating as well as identifying sources of error or poor data quality for a future implementation. Analysis of the data was undertaken using IBM $^{\circledR}$ SPSS $^{\circledR}$ Statistics v22 and Microsoft ${ }^{\circledR}$ Excel 2010.

\section{Results}

The initial data framework that resulted from Stage 1 of the project contained 16 data items across three dimensions: the women the model was designed for; the healthcare professionals working in the model; and aspects of the care provided by the model. Following
Table I. Final data elements in the MaCCS.

Final DSS version - short name

Target group indicator
Target group
Profession of designated maternity carer
Midwifery caseload indicator
Midwifery caseload size
Extent of continuity of carer
Profession of collaborative maternity carer
Routine relocation for intrapartum care and birth indicator
Expected setting for an antenatal care visit
Expected setting of birth
Postnatal visits in a residential setting indicator
Group session status, individual/group session descriptor
Planned medical visit indicator
Additional remote or rural service
Additional remote or rural services offered indicator
Expected length of time for postnatal visits in a residential setting
Major Model Category
Model Identifier
Establishment ID

Note. The full set of national data standards for the Model of Care Data Set Specification can be found at http://meteor.aihw.gov.au/content/index.pht $\mathrm{ml} /$ itemld/559937.

the formal data development process and national pilot in Stage 2, the resulting MoC DSS has 19 data elements (Table 1). The difference between the two sets of items was due to the addition of some 'administrative' data elements including an establishment identifier, model code and an indicator item (to prevent the use of a 'not applicable' value).

A total of 217 different models of care were classified across the 47 sites that participated in the pilot. The results of the national pilot of the DSS identified four data elements that had a significant error rate. This was due to participants not following the data standards correctly or not understanding the intent of the data elements. These data elements were replaced with new but related data elements. In addition to the four new data elements, three required additional permissible values and seven required additional instructions in the guide for use. These changes were then reviewed and endorsed by a working party of content experts. An examination of the source of the errors also highlighted the difficulty that respondents had in following some of the conditional requirements written into the data standards as well as some of the definitions. As the pilot was conducted using a survey instrument with limited programmability, conditionality for some data elements could not be built in. These sources of error don't reflect issues with the DSS itself and could be addressed through the use of a customised software data collection tool.

One of the key data elements in the DSS is the MMC that provides the list of broad model categories. These were identified predominantly through the published literature and refined through consultation with key stakeholders. The MMC and their descriptions are provided in Table 2. All of the models of care classified in the pilot could be grouped to one of ten MMC. Although not 
Table 2. Major Model Categories.

\begin{tabular}{|c|c|}
\hline Major Model Category & Description \\
\hline $\begin{array}{l}\text { Private obstetrician } \\
\text { (specialist) care }\end{array}$ & $\begin{array}{l}\text { Antenatal care provided by a private specialist obstetrician. Intrapartum care is provided in either a private or } \\
\text { public hospital by the private specialist obstetrician and hospital midwives in collaboration. Postnatal care is } \\
\text { usually provided in the hospital by the private specialist obstetrician and hospital midwives and may } \\
\text { continue in the home, hotel or hostel. }\end{array}$ \\
\hline $\begin{array}{l}\text { Private midwifery } \\
\text { care }\end{array}$ & $\begin{array}{l}\text { Antenatal, intrapartum and postnatal care is provided by a private midwife or group of midwives in } \\
\text { collaboration with doctors in the event of identified risk factors. Antenatal, intrapartum and postnatal care } \\
\text { could be provided in a range of locations including the home. }\end{array}$ \\
\hline $\begin{array}{l}\text { General Practitioner } \\
\text { obstetrician care }\end{array}$ & $\begin{array}{l}\text { Antenatal care provided by a GP obstetrician. Intrapartum care is provided in either a private or public } \\
\text { hospital by the GP obstetrician and hospital midwives in collaboration. Postnatal care is usually provided in } \\
\text { the hospital by the GP obstetrician and hospital midwives and may continue in the home or community. }\end{array}$ \\
\hline Shared care & $\begin{array}{l}\text { Antenatal care is provided by a community maternity service provider (doctor and/or midwife) in } \\
\text { collaboration with hospital medical and/or midwifery staff under an established agreement, and can occur } \\
\text { both in the community and in hospital outpatient clinics. Intrapartum and early postnatal care usually takes } \\
\text { place in the hospital by hospital midwives and doctors, often in conjunction with the community doctor or } \\
\text { midwife (particularly in rural settings). }\end{array}$ \\
\hline Combined care & $\begin{array}{l}\text { Antenatal care provided by a private maternity service provider (doctor and/or midwife) in the community. } \\
\text { Intrapartum and early postnatal care provided in the public hospital by hospital midwives and doctors. } \\
\text { Postnatal care may continue in the home or community by hospital midwives. }\end{array}$ \\
\hline $\begin{array}{l}\text { Public hospital } \\
\text { maternity care }\end{array}$ & $\begin{array}{l}\text { Antenatal care is provided in hospital outpatient clinics (either onsite or outreach) by midwives and/or } \\
\text { doctors. Care could also be provided by a multidisciplinary team. Intrapartum and postnatal care is } \\
\text { provided in the hospital by midwives and doctors in collaboration. Postnatal care may continue in the home } \\
\text { or community by hospital midwives. }\end{array}$ \\
\hline $\begin{array}{l}\text { Public hospital high } \\
\text { risk maternity care }\end{array}$ & $\begin{array}{l}\text { Antenatal care is provided to women with medical high risk/complex pregnancies by maternity care providers } \\
\text { (specialist obstetricians and/or maternal-fetal medicine subspecialists in collaboration with midwives) with an } \\
\text { interest in high risk maternity care in a public hospital. Intrapartum and postnatal care is provided by hospital } \\
\text { doctors and midwives. Postnatal care may continue in the home or community by hospital midwives. }\end{array}$ \\
\hline Team midwifery care & $\begin{array}{l}\text { Antenatal, intrapartum and postnatal care is provided by a small team of rostered midwives (no more than } \\
\text { eight) in collaboration with doctors in the event of identified risk factors. Intrapartum care is usually provided } \\
\text { in a hospital or birth centre. Postnatal care may continue in the home or community by the team midwives. }\end{array}$ \\
\hline $\begin{array}{l}\text { Midwifery Group } \\
\text { Practice caseload } \\
\text { care }\end{array}$ & $\begin{array}{l}\text { Antenatal, intrapartum and postnatal care is provided within a publicly-funded caseload model by a known } \\
\text { primary midwife with secondary backup midwife/midwives providing cover and assistance with } \\
\text { collaboration with doctors in the event of identified risk factors. Antenatal care and postnatal care is usually } \\
\text { provided in the hospital, community or home with intrapartum care in a hospital, birth centre or home. }\end{array}$ \\
\hline $\begin{array}{l}\text { Remote area maternity } \\
\text { care }\end{array}$ & $\begin{array}{l}\text { Antenatal and postnatal care is provided in remote communities by a remote area midwife (or a remote area } \\
\text { nurse) or group of midwives sometimes in collaboration with a remote area nurse and/or doctor. } \\
\text { Antenatal care may also be provided via telehealth or fly-in-fly-out clinicians in an outreach setting. } \\
\text { Intrapartum and early postnatal care is provided in a regional or metropolitan hospital (involving temporary } \\
\text { relocation prior to labour) by hospital midwives and doctors. }\end{array}$ \\
\hline $\begin{array}{l}\text { Private obstetrician } \\
\text { and privately } \\
\text { practising } \\
\text { midwife joint care }\end{array}$ & $\begin{array}{l}\text { Antenatal, intrapartum and postnatal care is provided by a privately practising obstetrician and midwife from } \\
\text { the same collaborative private practice. Intrapartum care is usually provided in either a private or public } \\
\text { hospital by the privately practising midwife and/or private specialist obstetrician in collaboration with } \\
\text { hospital midwifery staff. Postnatal care is usually provided in the hospital and may continue on in the home, } \\
\text { hotel or hostel by the privately practising midwife. }\end{array}$ \\
\hline
\end{tabular}

identified through the pilot, an additional MMC was added due to developments in national maternity policy that have led to an emerging model of care provided by a private obstetrician and private midwife in partnership.

\section{Discussion}

In Australia, standardised data about pregnancy, birth and the postnatal period have been collected and reported through the National Perinatal Minimum Data Set (PNMDS) since 1997 (Donnolley \& Li 2012). While the National Perinatal Data Collection (NPDC), which incorporates the PNMDS, has expanded over the past 18 years, the collection has never included information about models of care. With evidence from individual randomised controlled trials and a systematic review indicating that outcomes for women and babies vary under different models of care, it is important that this is monitored on a population level. The demand for an expansion of choices by women for their maternity care also raises a dilemma for health services that only have a finite budget and the responsibility to balance the provision of a choice of models of care with evidenced-based and economically viable services. Being able to accurately identify and classify models of care across Australia provides data to better inform service provision resulting in a lower cost to the health system as well as improved outcomes for mothers and babies.

The most effective way to monitor changes in practice and outcomes over time is through appropriate data collection and reporting. For the first time, the MaCCS will enable health services to collect data about the models of 
care being offered to women and to analyse that based not only on the category of the model of care but on the individual characteristics of the models themselves. For example, outcomes for women and babies in models targeted at a specific group of women could be examined in further detail to determine if there is any association between the model of care and outcomes. Using the target group 'Aboriginal and Torres Strait Islander identification' for example, an analysis could be undertaken by identifying all models of care in the MoC DSS data collection for models with that value in 'Target Group' and then selecting all the women's records from the NPDC for women in those models. Those records could then be analysed for differences in their outcomes based on other characteristics of their care such as the MMC, designated maternity carer, extent of continuity of carer etc. In this way analysis of outcomes of different groups of women can be undertaken at a far more granular level than purely based on the name of their model of care or even by the profession of their carers (as has been the case in the past). This could better inform service development or policy regarding more effective models of care for selected groups of women. Further, it will also be possible to monitor women's movements between different models of maternity care throughout pregnancy when the Model ID is recorded in their health records at different stages of pregnancy.

Results of both Stage 1 and Stage 2 of the MaCCS development demonstrated that the data elements underpinning the classification system were suitable to describe models of care throughout Australia. The process of repeat consultation with stakeholders in Stage 1, utilising the evidence from the published and grey literature and the input of content experts meant that there were very few changes suggested by participants in the pilot. In particular there were very few additional permissible values required and all of the models of care classified in the pilot could be assigned to one of the MMC. The results also identified the need for an electronic data collection tool with programmed business rules and logic that would ensure the data standards were followed and to assist respondents in correctly answering the questions.

The MaCCS is a novel system for defining models of care that has not been attempted anywhere else in the world. By classifying models of care based on the characteristics of the models, including their MMC (but not solely using the MMC) the MaCCS can also accommodate models developed into the future. The classification is not reliant on local terminology or naming and each of the data elements can be adapted through the addition of more permissible values if required as changes to maternity care arise. High quality, safe, woman-centred maternity care is not a 'one-size-fits-all' approach and variations to models of care continue to evolve as new evidence becomes available for improving maternity care. The MaCCS will enable individual health services, jurisdictional health departments and the Commonwealth to report on outcomes for mothers and babies under different models of care and examine the potential influences of different model characteristics to inform health policy and service provision for maternity care in a way that has not been possible before.

\section{Limitations}

Although the MaCCS has undergone a thorough content validation and a limited useability evaluation through the process of development (including the use of the participatory action research design and the national pilot), there are limitations to this validation. As a novel classification system there is currently no existing system or 'gold standard' to validate the MaCCS against, which makes criterionrelated validation impossible. Similarly, the MaCCS contains single measures of individual characteristics of models of care making construct validation using repeated measures impossible. This leaves the remaining possible methods of validation to be an assessment of the repeatability and reproducibility of the MaCCS. A validation study of this nature is required to show that while the theoretical framework of the MaCCS is valid according to the published literature and content experts, it is also valid when applied in practice. A validation study of the MaCCS to assess its repeatability and reproducibility is currently underway as an independent external research project to the Commonwealth-funded NMDDP.

\section{Conclusion}

Where once a woman had limited choice about the pregnancy and birth care she received in Australia, today her choices are rapidly expanding. Models of care are evolving in response to both consumer demand and a widening evidence-base of the benefits of new models of care. Timely data collection and reporting is required to ensure that outcomes for women and babies are not compromised by this expansion of models of care and that there is not an increasing unwarranted cost burden on the health system. Recognising that the existing perinatal data collection in Australia did not adequately identify or record data about models of care, a novel classification system, the MaCCS, has been developed to address this gap. This project demonstrated one approach to the development of a world-first classification system for maternity models of care. The MaCCS will provide a much-needed standardised terminology to describe models of care and is also expandable in the future as models of care evolve. The process used to develop the MaCCS could be replicated to develop similar classification systems for models of care in other heath areas.

\section{Acknowledgements}

The authors would like to acknowledge the Commonwealth Department of Health for funding the National Maternity Data Development Project under which the MaCCS was developed, the Australian Institute of Health and Welfare for permission to publish this work and the members of the MaCCS Working Party who contributed to the project. 


\section{References}

Australian Institute of Health and Welfare (2007) A guide to data development. Catalogue no. HWI 94. Canberra, AIHW.

Australian Institute of Health and Welfare (2014a) Foundations for enhanced maternity data collection and reporting in Australia: National Maternity Data Development Project Stage 1. Cat. no. PER 60. Canberra, AIHW.

Australian Institute of Health and Welfare (2014b) Nomenclature for models of maternity care: literature review, July 2012 Foundations for enhanced maternity data collection and reporting in Australia: National Maternity Data Development Project Stage 1. Cat. no. PER 62. Canberra, AIHW.

Australian Institute of Health and Welfare (2015) Admitted patient care 2013-14: Australian hospital statistics. Health services series no. 60. Cat. no. HSE 156. Canberra, AIHW. Available at: http://www.aihw.gov.au/WorkArea/Download Asset.aspx?id=60129550480 (accessed 2 April 2015).

Amatayakul M (2009) Electronic Health Records - a practical guide for professionals and organizations. Chicago, American Health Information Management Association.

Australian Health Ministers' Conference (2011) The National Maternity Services Plan. Canberra, Commonwealth of Australia. Available at: http://www.health.gov.au/internet/main/ publishing.nsf/Content/maternityservicesplam (accessed 1 April 2015).

Baum F, MacDougall C and Smith D (2006) Participatory action research. Journal of Epidemiology and Community Health 60(10): 854-857.

Commonwealth of Australia (2009) Improving maternity services in Australia: the report of the maternity services review. Canberra, Commonwealth of Australia. Available at: http://www. health.gov.au/internet/main/publishing.nsf/Content/maternityservicesreview-report (accessed 6 April 2015).
Davidson P, Hickman L, Graham B, et al. (2006) Beyond the rhetoric: what do we mean by a 'model of care'? The Australian Journal of Advanced Nursing 23(3): 47-55.

Donnolley N and Li Z (2012) Perinatal National Minimum Data Set compliance evaluation 2006 to 2009. Perinatal statistics series no. 26. Cat. no. PER 54. Sydney, Australian Institute of Health and Welfare National Perinatal Epidemiology and Statistics Unit.

Hilder L, Zhichao Z, Parker M, et al. (2014) Australia's mothers and babies 2012. Perinatal statistics series no. 30. Cat. no. PER 69. Canberra, AIHW. Available at: http://www.aihw.gov.au/ publication-detail/?id=60129550033 (accessed 28 January 2015).

Homer C, Brodie P and Leap N (2008) Getting started: what is midwifery continuity of care? In Homer C, Brodie P and Leap $\mathrm{N}$ (eds) Midwifery continuity of care: a practical guide. Chatswood, Elsevier Australia: 1-24.

Jutel A (2011) Classification, disease, and diagnosis. Perspectives in Biology and Medicine 54(2): 189-205.

Queensland Health (2000) Changing models of care framework. Brisbane, Queensland Government. Available at: http://www. health.qld.gov.au/publications/change_management/Care_ Framework.pdf (accessed 24 February 2012).

Sandall J, Soltani H, Gates S, et al. (2013) Midwife-led continuity models versus other models of care for childbearing women. Cochrane Database of Systematic Reviews. Available at: http://onlinelibrary.wiley.com/doi/10.1002/14651858. CD004667.pub3/abstract (accessed 22 August 2013).

Walker J (2011) Maternity data in Australia: a review of sources and gaps. Bulletin no. 87. Canberra, AIHW.

World Health Organization (2011) World health statistics 2011. Geneva, WHO. Available at: http://www.who.int/whosis/whostat/2011/en/ (accessed 11 April 2012). 